\title{
EVALUATION OF DIAGNOSTIC CRITERIA FOR ANKYLOSING SPONDYLITIS: A COMPARISON OF THE ROME, NEW YORK AND MODIFIED NEW YORK CRITERIA IN PATIENTS WITH A POSITIVE CLINICAL HISTORY SCREENING TEST FOR ANKYLOSING SPONDYLITIS

\author{
BY HENK SIMON GOEI THE', MALCOLM M. STEVEN ${ }^{2}$, SJEF M.
} VAN DER LINDEN ${ }^{3}$, AND ARNOLD CATS ${ }^{2}$ \\ The Departments of Rheumatology of 'De Wever Ziekenhuis, Heerlen, The Netherlands, '2University of Leiden, The Netherlands, and ${ }^{3}$ University of Bern, Switzerland
}

\begin{abstract}
SUMMARY
The modified New York criteria for the diagnosis of ankylosing spondylitis were evaluated and compared to the older criteria in 151 patients, referred to hospital because of low back pain and who had a positive clinical history screening test for ankylosing spondylitis and in 31 controls with noninflammatory back pain. Radiological examination of the sacro-iliac joints showed sacro-iliitis in 124 (82\%) from the 151 with inflammatory back pain. In $110(72 \%)$ of those patients a diagnosis of definite ankylosing spondylitis according to the classical New York criteria could be made and they had a prevalence of HLA-B27 of $84 \%$. Application of the modified New York scheme increased the number of patients meeting the criteria for definite ankylosing spondylitis to all 124 patients with sacro-iliitis, and $82 \%$ of this group carried HLA-B27.

The classical New York criteria of 'limitation of the lumbar spine in three directions' and of 'limitation of chest expansion' appeared to reflect disease duration rather than help in the initial diagnosis.
\end{abstract}

KEY wORDS: Clinical history screening test, Diagnostic criteria, HLA-B27, Ankylosing spondylitis.

THE distinction between back pain due to mechanical causes and that resulting from inflammatory conditions such as ankylosing spondylitis (AS) can be difficult for the clinician as well as the epidemiologist. A screening test for AS, based on the clinical history was defined by Calin et al. (1). AS is characterized by insidious onset of back pain in a patient younger than 40 years, persisting for at least three months, associated with morning stiffness and improving with exercise and the test is considered to be positive if at least four of these five items are answered affirmatively. More elaborate diagnostic criteria designed for scientific studies and including the findings of physical and radiological examination were framed in Rome (2) and revised in New York (NY) (3) (Tables I and II). Recently, modified New York criteria (MNY) have been proposed (4) (Table I). The main points of divergence from the previous NY are that the existing second clinical criterion concerning the symptom of backache, which has a low specificity $(4,5)$. is replaced by a slight modification of the more specific first Rome criterion about backache and that all the clinical criteria are given equal weight. In addition the combined clinical and radiological findings are more liberally interpreted.

Submitted 6 November 1984; revised 18 February; accepted 19 March 1985.

Address correspondence to: Dr. Henk Simon Goei The, Department of Rheumatology, De Wever Ziekenhuis, Postbox 4446, 6401 CX Heerlen, The Netherlands. 


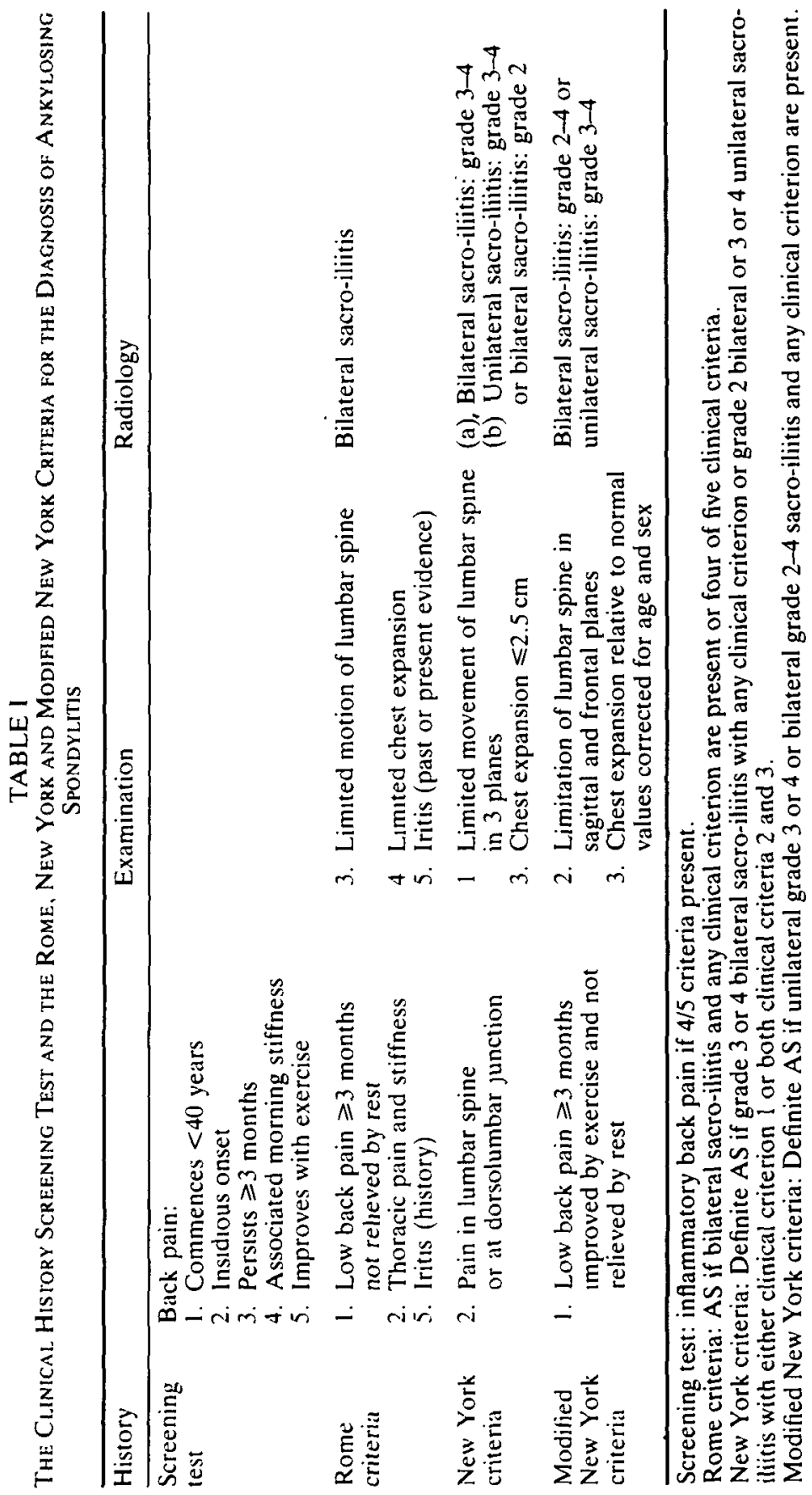



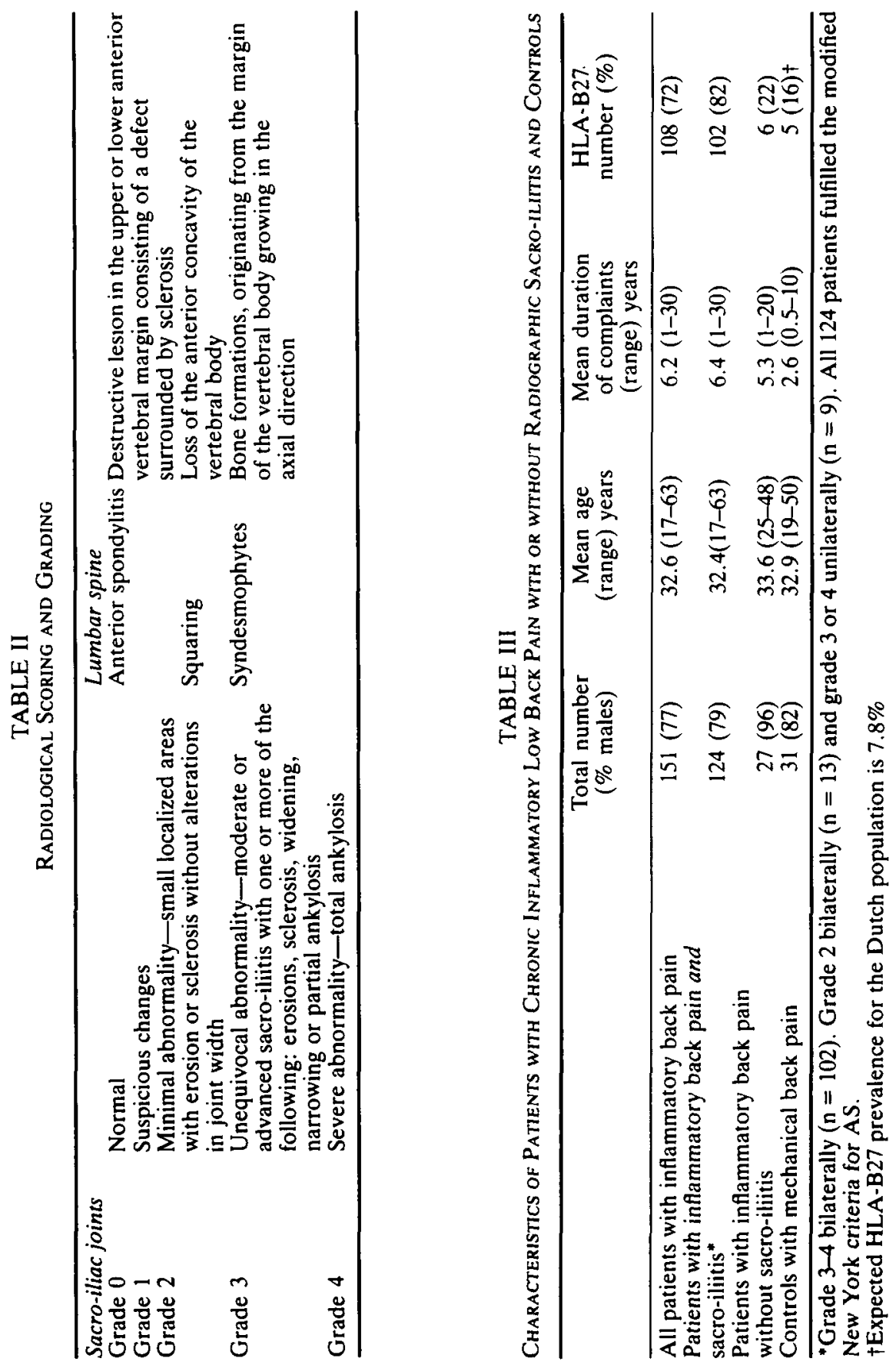
We have evaluated the prevalence of AS according to the Rome, the NY and the MNY in 151 patients, referred to hospital because of low back pain, who had a positive clinical history screening test for AS and in 31 controls with mechanical back pain. We also evaluated the influence of the duration of the disease on the sensitivity of the diagnostic criteria.

\section{PATIENTS AND METHODS}

All patients who were referred between 1978 and 1982 to the rheumatological unit of the De Wever Hospital with complaints of low back pain were screened for the presence of inflammatory low back pain according to the aforementioned criteria (1). A total of 151 patients fulfilled these criteria and were considered to have inflammatory back pain. The patients were referred by orthopaedic surgeons ( 32 patients), other specialists ( 20 patients) and general practitioners ( 99 patients). Of the 99 patients referred by general practitioners, 59 had previously been seen by other specialists for the same complaints. As controls, a consecutive group of 31 patients referred to the same department between 1979 and 1980 who did not meet the criteria for inflammatory back pain (1) were taken. At examination none of the controls showed evidence of nerve root compression and 12 had lumbar disc degeneration apparent radiologically. These 31 patients were therefore concluded to have noninflammatory back pain. The mean age in the patient and control group was the same (Table III) and the sex distribution was also comparable. The total group of patients with inflammatory back pain but not the controls had an increased prevalence of HLA-B27 $(72 \%)$.

The range of motion of the lumbar spine was investigated in four directions (forward flexion, lateral flexion to both sides and extension) and was expressed as either limited or nonlimited on a purely subjective basis (5). Chest expansion was measured (in $\mathrm{cm}$ ) at the level of the fourth intercostal space. The clinical criteria for AS were evaluated without knowledge of the radiology and the HLA status. HLA typing for the presence of B27 was done in all subjects using the Histognost B27 test (Behringwerke AG).

After informed consent, radiological examination was performed and included an antero-posterior pelvic view, and antero-posterior lateral and oblique views of the lumbar spine. All radiographs were read 'blindly' by two radiologists (see Acknowledgements) and one rheumatologist (GT). A sign, for example the presence of sacro-iliitis, was considered to be present when at least two of the three observers noted it.

Sacro-iliac radiographs were graded according to the NY criteria (3) (Table II). Lumbar spine radiographs were read for the presence of anterior spondylitis, squaring and syndesmophyte formation (Table II). Films of patients were mixed with the films of controls before reading.

\section{Statistics}

Use was made of the chi square test with Yates' correction.

\section{RESULTS}

The characteristics of the patients and the controls are shown in Table III. The number of patients meeting the obligatory number of criteria for the diagnosis of definite AS according to the Rome, NY and MNY criteria is shown in Table IV. The MNY are, in the presence of a positive clinical history screening test, obviously more sensitive than the Rome or NY criteria (124 versus 115 and 110 cases of definite AS) and the additional cases also show a high prevalence of HLA-B27. The prevalence of clinical Rome, NY and MNY criteria in patients and controls with regard to the radiological grading of the sacro-iliac joints is shown in Table V. The higher specificity of the first MNY criterion in contrast to the 
TABLE IV

Number of 151 Patients with a Positive Screening Test for Ankylosing Spondylitis meeting Criteria for Definite Diagnosis according to the Rome, New York and Modified New York SCHEMES

\begin{tabular}{lcc}
\hline Diagnostic scheme & $\begin{array}{c}\text { Number of } \\
\text { patients }(\%)\end{array}$ & $\begin{array}{c}\text { Number of HLA-B27 } \\
\text { positive (\%) }\end{array}$ \\
\hline Rome: Overall & $115(76)$ & $94(81)$ \\
Radiological ${ }^{*}+$ one clinical criterion & $115(76)$ & $94(81)$ \\
New York: Overall & $110(73)$ & $92(84)$ \\
Grade ${ }^{*}$ 3b+4b sacro-ilitis + one clinical criterion & $102(68)$ & $87(85)$ \\
Grade 2b or 3u sacro-iliitis + clinical criterion 1, & & \\
or + clinical criteria (2 + 3) & $124(82)$ & $5(63)$ \\
Modified New York: Overall & $102(68)$ & $102(82)$ \\
Grade 3b-4b sacro-iliitis + one clinical criterion & $22(15)$ & $87(85)$ \\
Grade 2b or 3u sacro-iliitis + one clinical criterion & & $15(68)$ \\
\hline
\end{tabular}

$* 2,3,4=$ radiological grades; $u=$ unilateral; $b=$ bilateral.

TABLE V

The Prevalence (\%) of Rome and New York (NY) and Modified Ny (MNY) Criteria in Patients With Inflammatory or Mechanical Back Pain

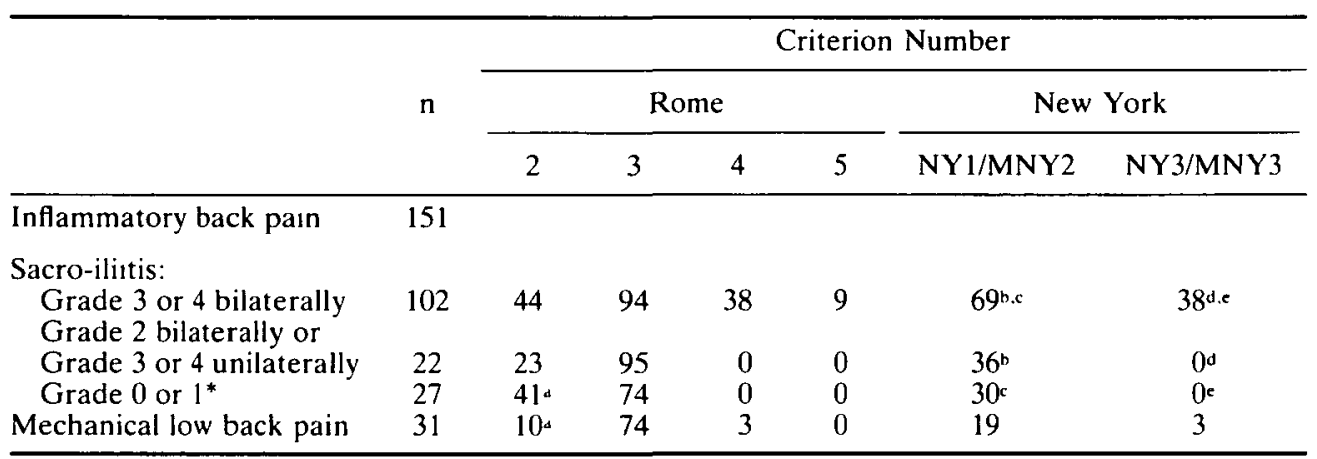

*Unilateral grade 2 was not found in these groups.

Chi square test with Yates' correction, comparing: a with $a, \chi^{2}=6.00, p<0.02 ; b$ with $b, \chi^{2}=6.75$, $\mathrm{p}<0.01 ; \mathrm{c}$ with $\mathrm{c}, \chi^{2}=12.00, \mathrm{p}<0.001$; $\mathrm{d}$ with $\mathrm{d}, \chi^{2}=10.56, \mathrm{p}<0.001 ; \mathrm{e}$ with $\mathrm{e}, \chi^{2}=13.04, \mathrm{p}<0.001$.

second NY criterion in excluding cases of noninflammatory back pain is apparent. The 27 patients with inflammatory back pain without radiological sacro-iliitis had thoracic pain and stiffness significantly more often than the 31 controls (Table V), and only six (22\%) of these 27 patients were HLA-B27 positive. A comparison of radiological abnormalities with limitation of spinal movement in four directions (NY 1, MNY 2) shows restricted motion in more than two thirds of those with grade 3-4 bilateral sacro-iliitis but in only one third of those with lesser degrees and this difference is statistically significant (Table V). Limited chest expansion is only seen in the patients with more severe (grade 3-4) sacro-iliitis. The prevalence of HLA-B27 is about the same in the patients with grade 3-4 bilateral and grade 2 bilateral or grade 3-4 unilateral sacro-iliitis, while the prevalence of HLA-B27 in the patients without radiological sacro-iliitis does not differ from the controls (Tables III and IV).

Limitation of motion in the lumbar spine and thoracic pain and stiffness increased significantly in patients with more than five years duration of symptoms (Table VI) whereas 
TABLE VI

Duration of Back Pain Related to Signs and Other Symptoms in 124 Patients with Definite AS according to the Modified New York Criteria

\begin{tabular}{lccc}
\hline & \multicolumn{3}{c}{ Duration of infammatory low back pain } \\
\cline { 2 - 4 } & $\begin{array}{c}0-4 \text { years } \\
(\mathrm{n}=62) \\
\text { Number }(\%)\end{array}$ & $\begin{array}{c}5-9 \text { years } \\
(\mathrm{n}=30) \\
\text { Number }(\%)\end{array}$ & $\begin{array}{c}\geqslant 10 \text { years } \\
(\mathrm{n}=32) \\
\text { Number }(\%)\end{array}$ \\
\hline $\begin{array}{l}28(45)^{\mathrm{a}} \mathrm{b} \\
\text { Limitation of motion of lumbar spine in } 4 \text { directions }\end{array}$ & $\begin{array}{l}23(82)^{\mathrm{a}} \\
\text { Limitation of chest expansion } \geqslant 2.5 \mathrm{~cm}\end{array}$ & $27(87)^{\mathrm{b}}$ \\
Thoracic pain and stiffness & $10(16)^{\mathrm{c}}$ & $10(36)$ & $17(55)^{\mathrm{c}}$ \\
\hline
\end{tabular}

Chi square test with Yates' correction: (a) $\chi^{2}=6.898, \mathrm{p}<0.009$; (b) $\chi^{2}=11.803, \mathrm{p}<0.001$; (c) $\chi^{2}=$ $9.756, \mathrm{p}<0.002 ;$ (d) $\chi^{2}=23.906, \mathrm{p}<0.001 ;$ (e) $\chi^{2}=16.18, \mathrm{p}<0.001$.

TABLE VII

Radiological Involvement of the Lumbar Spine Related to Signs and Symptoms in 124 Patients with Definite AS according to the Modified New York Criteria

\begin{tabular}{lcc}
\hline & \multicolumn{2}{c}{ Radiological lumbar spine involvement } \\
\cline { 2 - 3 } & $\begin{array}{c}\text { Absent }(\mathrm{n}=69) \\
\text { Number }(\%)\end{array}$ & $\begin{array}{c}\text { Present }(\mathrm{n}=55) \\
\text { Number }(\%)\end{array}$ \\
\hline $\begin{array}{l}\text { Limitation of motion of lumbar spine in 4 directions } \\
\text { Limitation of chest expansion } \geqslant 2.5 \mathrm{~cm}\end{array}$ & $29(42)^{\mathrm{a}}$ & $49(89)^{\mathrm{d}}$ \\
Thoracic pain and stiffness & $9(13)^{\mathrm{b}}$ & $30(55)^{\mathrm{b}}$ \\
\hline
\end{tabular}

Chi square test with Yates' correction: (a) $\chi^{2}=27.07, p<0.001$; (b) $\chi^{2}=22.56, p<0.001$; (c) $\chi^{2}=20.62$. $\mathrm{p}<0.001$.

limited chest expansion increased more gradually with time. Combined radiological involvement of the sacro-iliac joints and the lumbar spine was associated with a significantly increased prevalence of these three clinical criteria (Table VII).

HLA-B27 was present in $72 \%$ of the patients with inflammatory back pain and in $16 \%$ of the controls. The prevalence of AS in the $108 \mathrm{HLA}-\mathrm{B} 27$ positive patients with inflammatory back pain was $94 \%$, but remained as high as $51 \%$ (22) of the 43 inflammatory back pain patients negative for HLA-B27.

\section{DISCUSSION}

Diagnostic criteria have been framed for AS (2-5) and other rheumatic conditions to aid clinicians and epidemiologists in different centres to ensure comparability between groups of patients under study (4), but may aid clinical diagnosis although they have not been prospectively tested in this setting. The criteria for AS, as stated in Rome (2) and New York (3) have been criticized on grounds of sensitivity and specificity $(5,6)$. Recently a revised set of criteria (MNY) has been proposed (4). In the present study the modified criteria are compared to the classical ones and all three sets of criteria for AS are tested in a group of hospital out-patients with a positive clinical history screening test for AS (1).

The clinical history screening test for AS was initially reported to have a sensitivity of $95 \%$ in 42 HLA-B27 positive patients with definite AS according to the NY (1). A specificity 
of $95 \%$ was also found in 82 controls, including 21 HLA-B27 negative orthopaedic patients although in all groups the screening test was applied to patients after the diagnosis was known.

Our results demonstrate the value of the test as a screening procedure for AS in patients with low back pain attending a rheumatology out-patient department as only 27 of the 151 patients without radiological sacro-iliitis (18\%) did not fulfil the MNY for definite AS. A bias in the referral pattern could have contributed to our finding of a high prevalence of $A S$ among inflammatory back pain patients as we had stressed the importance of the screening test for AS at several postgraduate meetings. Therefore our data do not permit any estimation of the prevalence of AS in all patients with chronic inflammatory back pain in the open population. Nonetheless, a positive clinical history screening test for AS justifies a radiological examination of the sacro-iliac joints and follow-up of the patients if radiological sacroiliitis cannot (yet) be demonstrated beyond doubt. As all diagnostic criteria rely to a great (2) or absolute (3-4) extent on the presence of radiological sacro-iliitis to reach a diagnosis of definite AS, the problem of early diagnosis, before the onset of radiological sacro-iliitis remains to be solved.

In the MNY each of the clinical criteria has an equal weight and the diagnosis of definite AS can be made in the presence of sacro-iliitis grade $2-4$ bilaterally or grade $3-4$ unilaterally in the presence of only one clinical criterion. This leads to an increased sensitivity of the MNY as compared to the NY. In our opinion, this higher sensitivity is justified and valid as the patients with mechanical back pain were excluded by the new criteria and in the group of 14 patients in whom the diagnosis of definite AS could only be reached by application of the MNY, the HLA-B27 prevalence was $71 \%$ which is comparable with the AS patients meeting the NY criteria. Also, the mean duration of complaints was shorter, 3.8 years versus 6.2 years for the whole group of 151 patients. These results suggest that the additional patients satisfying the MNY criteria are relatively early cases of AS.

Significant differences for the presence of the second and third MNY and the second Rome were found when the prevalences of these criteria were related to the duration of the disease (Table VI) and the same applies to radiological involvement of the lumbar spine (Table VII). These findings suggest that these criteria are less useful for the diagnosis of early disease, especially during the first five years of symptoms when the first MNY seems to be more useful.

The use of tissue-typing is not included in any set of diagnostic criteria although there is a high degree of association between HLA-B27 positivity and definite AS. Used in conjunction with the screening test alone the rate of false negative AS cases (18\% in this series) and false positives (22\% in this series) is unacceptably high (Table III). Jajic (7) studied 652 patients with back pain of more than three months' duration but only 128 of the 276 , who were HLA-B27 positive, had definite AS. In the present study $51 \%$ of the 43 HLA-B27 negative patients with inflammatory back pain met the clinical and radiological criteria for AS and would have been excluded by criteria which include HLA-B27 positivity. There were no apparent differences between the HLA-B27 positive and negative groups, and tissue typing should not therefore be included in diagnostic criteria because of its poor sensitivity and specificity. However, there appears to be a group of patients with inflammatory back pain without sacro-iliitis, but with a high prevalence of HLA-B27 (8). Tissue-typing will therefore remain important for classifying these subgroups of spondylitic diseases and possibly for defining the pathogenetic significance of HLA markers.

In conclusion, the clinical history screening test has proved valuable for the detection of AS in patients referred to a rheumatology out-patient department with back pain. The value of the test in general practice and in the open population has not yet been established. The 
newly described MNY applied to patients with inflammatory back pain, appear to be more sensitive for detecting early cases of AS than the previous criteria and have comparable specificity. The individual criteria relating to restriction of spinal movement and chest expansion are apparently related to duration of disease and might therefore have additional value over their use in diagnosis.

\section{ACKNOWLEDGEMENTS}

The authors wish to express their gratitude to Gerard Goedhard MD, and Albert Lemmens MD, for reading the radiographs, and to Chris de Waal van Anckeveen for the statistical evaluation. Tissuetyping was performed by the Haematology Laboratory of the De Wever Ziekenhuis in Heerlen (Jan van Wersch MD). The participation of the patients in this study is gratefully acknowledged.

\section{REFERENCES}

1. Calin A, Porta J, Fries JF, Schurman DJ. Clinical history as a screening test for ankylosing spondylitis. JAMA 1977;237:2613-14.

2. Kellgren JH, Jeffrey MR, Ball J. The epidemiology of chronic rheumatism, vol. I. Oxford: Blackwell, 1963;326-7.

3. Bennet PH, Wood PHN. Population studies of the rheumatic diseases. Amsterdam: Exerpta Medica Foundation, 1968:456-7.

4. Van der Linden S, Valkenburg HA, Cats A: Evaluation of diagnostic criteria for ankylosing spondylitis. Arthritis Rheum 1984;27:361-8.

5. Moll JMH, Wright V. New York clinical criteria for ankylosing spondylitis. Ann Rheum Dis 1973; 32:354-63.

6. Moll JMH. Diagnostic criteria and their evaluation. In: Moll JMH, ed. Ankylosing spondylitis. Edinburgh: Churchill Livingstone, 1980;137-51.

7. Jajic I. The role of HLA-B27 in the diagnosis of low back pain. Acta Orthop Scand 1979;50:411-13.

8. Khan MA, Van der Linden S, Valkenburg HA, Kushner I, Cats A. Symptomatic ankylosing spondylitis without radiographic sacroiliitis in HLA-B27 positive relatives. Arthritis Rheum 1985;28: $40-44$. 